\title{
Various Tongues Updated: Mediatisation, Visualisation and the Digitalisation of Social Multilingualism - the Continuing Role of English
}

\author{
Allan JAMES \\ University of Klagenfurt (Austria)
}

\begin{abstract}
The present paper revisits the publication Vielerlei Zungen (2003) and examines whether some of the tentative conclusions of the volume as to the then analysed sociocultural traits of practised multilingualism have been substantiated over time. Indeed, the observed development of pluralistic and shifting linguistic identities, of multilingual discourse spaces and the associated 'crossings' availed to language users all would appear to be confirmed and even intensified in the time period since. Above all, the latterly massively increased mediatisation of language, its visualisation and in particular the digitalisation of social communication on a global scale have led to a re-shaping of social heteroglossia/polyphony as a contextually constructed multimodal and multi-media
\end{abstract} total-communicative event in which multilingual discourse spaces flourish. At the same time, the affordances (and constraints) of the digital medium itself have led to a sociocultural re-positioning of the languages which constitute the linguistic resources employed in such exchanges, not least with regard to 'English' in this respect. By adducing relevant research worldwide, the paper will examine the role that anglophony as anglography now fulfils as both a codal and modal resource in online multilingual discourse.

Keywords: multilingualism, mediatisation, visualisation, digitalisation, English

(c) by the author; allan.james@aau.at

Colloquium: New Philologies, Volume 5, Issue 2 (2020)

doi: 10.23963/cnp.2020.5.2.2

Stable URL: https://colloquium.aau.at/index.php/Colloquium/article/view/124

This work is licensed under a Creative Commons Attribution 4.0 International License (CC BY 4.0). 


\section{Introduction}

The starting point for the present discussion is a review of some of the main findings of contributions to the multilingualism volume Vielerlei Zungen (James 2003) and an assessment of their relevance for a sociocultural understanding of modes of multilingualism as practised in 2020. Significantly, the sub-title of the volume is formulated as Mehrsprachigkeit + Spracherwerb + Pädagogik + Psychologie + Literatur + Medien (i.e. "Multilingualism + Language Acquisition + Education + Psychology + Literature + Media") and as such signals an approach to "Various Tongues" as they are mediated in the sociocultural domains indicated. Practised multilingualism in the contexts analysed is interpreted variously as being subversive, relations-changing with regard to the component languages involved or as itself constituting an intercultural discourse (the contributions on literary multilingualism by, respectively, Kucher, Sallager and Strutz), as couched as (masked) performances (the contribution by Larcher), as being linguistically undifferentiatedly and unreflectedly realised by young children (the contributions on multilingualism in language acquisition by Schneider, and kindergarten by Gombos) and as constituting an aterritorial cultural space itself (the contribution on multilingualism in the 'free radio' media sector by Busch). Beyond these domain-specific observations, more general conclusions drawn from the analysis of practised multilingualism are that it reflects the essence of a user's language capacity - linguality ("Sprachigkeit") - as by nature varied and variant within and between individual languages and lects, which in turn signals code-switching and code-mixing practices as normal language use (contribution by James). Furthermore, pluralistic language identities are regarded equally as the norm, an extended interpretation being that the contextual subjectivities of the late/post-modern language user are themselves discursively created (contribution by James). In this context, also the particular nature and role of English as a lingua franca in a multilingual world is considered, where it is concluded that the language in this function itself confirms the essence of linguality as a varied and variant language capacity, itself mediates pluralistic identities and as such has a role in the formation of the discursively created subjectivities of multilingual language users referred to (contribution by James).

In the following, these conclusions on a number of the sociocultural and sociolinguistic traits of multilingualism as observed in 2003 will be examined, adjusted and expanded in light of the changing sociocultural practices of subsequent years. 


\section{Languages in Use: from Command of Verbal Code to Deployment as Semiotic Resource}

In the contributions to Vielerlei Zungen it could be noted that there is no discussion of a particular language defining the sociocultural identity of its users tout court in the multilingual contexts analysed. However, at the same time the main conception projected of 'a language' is that of a total sociocultural and linguistic construct, a repository of culture, linguistically structured, which is an 'object' to be acquired and realised as a fundamental component of socialisation. Learners and users of 'a language', unless otherwise stated, attempt to internalise a particular total verbal code of expression, as institutionalised in grammars and dictionaries, with its particular sociocultural significance. Languages are used, taught and learnt in the first instance as stable context-independent and self-contained bodies of structured verbal knowledge and cultural semiotics. It is in this essence that languages are mediated in the multilingual contexts addressed in the original volume and the pluralistic identities of multilinguals are predicated on an understanding of 'languages' as conceived of in this manner. In a developmental perspective, the simultaneous or successive acquisition of different languages as thus understood (e.g. as in the bilingual acquisition of children or the staged introduction of languages in an educational setting) is sometimes seen to be equivalent to a multiplied monolingualism (cf. Grosjean 1989). Also, the treatment of English as a lingua franca in the volume in the first instance reflects this monolithic conception of 'a language' as a fixed and bounded object, which other contemporary research had attempted - unsuccessfully - to describe and institutionalise as a full variety of English in its own right.

By contrast, the 'social turn' in linguistics of the late $20^{\text {th }} /$ early $21^{\text {st }}$ century and the increasing prominence of social-constructivist approaches to language in use has led to a highlighting on the one hand of the contextual conditioning of linguistic form and on the other of the creative potential of linguistic form to shape contexts of use itself. From the perspective of multilingualism, the various languages (= "Vielerlei Zungen") present in a heteroglossic discoursal space are seen, primarily and selectively, to provide local sources of (social) semiotic expression, i.e. where "Multilingualism should not be seen as a collection of 'languages' that a speaker controls, but rather as a complex of specific semiotic resources, some of which belong to a conventionally defined 'language" (Blommaert 2010, 102), while others constitute "concrete accents, language varieties, registers, genres, modalities such as writing - ways of using language in particular communicative settings and spheres of life" (ibid., 202). This view of multilingualism, as focussed on the contextual deployment of polyphonic resources of meaning, is seen as a natural consequence of the social, cultural and lingual mixing that has intensified as a consequence of 
globalisation. It, in turn, can be linked back to Appadurai’s (1996) earlier anthropological theorising of the cultural dimensions of globalisation in terms of changed "-scapes" here perhaps specifically as "linguoscapes", which more recently have been conceptualised as the product of global 'transcultural flows' (Pennycook 2007).

\section{From Code-Mixing to Translanguaging}

The favoured locus of such multilingual practices is that of social communication among younger generation language users who employ alternating linguistic resources for the expression of socially relevant local meanings, including the discursive creation and projection of personal subjectivities. These practices involve a considerable amount of what in structural linguistic terms would be referred to as 'code-switching' or 'code-mixing', but within the more current framework of analysis constitute the sociocultural communication activity of 'translanguaging' (cf., e.g. Li 2017), as users draw on, and themselves create the various specific linguistic resources semiotically relevant to the particular context of exchange. The linguistic substance produced is therefore a bricolage of partial lects, each of which signalling its own social semiotics and exhibiting foremostly the 'semiodiversity' as opposed to the 'glossodiversity' of language(s) in Halliday's (2007) terms (see also James 2009). However, it must be remembered that, at the same time, even the 'part-languages' selectively employed in such social communication do not entirely lose the context-independent sociocultural identities associated with the 'whole languages' they derive from. The total discourse linguistically expressed, therefore, displays a shifting semiotic mix of context-sensitive and context-free social and sociocultural reference.

Earlier sociolinguistic research on the 'translanguaging' practices referred to in particular analysed the language 'crossing' behaviours of young urban males of mixed autochtonous and allotochtonous origin in oral conversation scenarios, in which not just 'language'-switching and -mixing constituted the general discourse norm, but also mimicry of language styles and accents of language users both in praesentia and in absentia were prominent (see, e.g. Rampton (1995) on the language 'crossing' of adolescents in an urban environment in the U.K. and Jörgensen (e.g. 2008) on the 'polylanguaging' of equivalent subjects in Copenhagen, Denmark). However, it is the increasing general mediatisation of language in the public sphere, its visualisation and above all the subsequent digitalisation of social communication in the (semi-)private sphere that signal a significant general shift in the way multilingualism is practised at the interpersonal level. 


\section{The Mediatisation of Language and Multilingualism}

That the forms that language takes are co-dependent on the medium through which it is communicated is not necessarily a recent revelation in linguistic studies, for ever since the development and spread of interpersonal communication media, from the telegraph to telephone to computer-mediated communication, it has been observed that the technological conditions of each medium themselves constrain the forms of language used. For instance, while brevity of sentence and word structure characterise telegraphy and reduced voice frequency bands telephony, also the expressive limits of electronic keyboards condition the form of online language. Additionally, the onset of the mass communication media of newspapers, phonogram, radio, cinema and television and now internet have also consistently led to a particular 'mediatisation' of language in that new modes and genres of communication have developed within these media (much as they have with interpersonal communication media), which are themselves characterised by their own linguistic features (e.g. Androutsopoulos 2014; 2016).

From the perspective of multilingualism, the accelerating mediatisation of language, in the mass media discernible as of the latter third of the $20^{\text {th }}$ century, in the interpersonal media as of the late $20^{\text {th }}$ /early $21^{\text {st }}$ century, has led to an increasing hybridisation of language used. Studies of the partially 'hybridised' language typical of particular genres associated with print media, radio and television have established a significant increase in the use of 'foreignisms' in such discourses; for example, the use of anglicisms in germanophone media (cf. e.g., Onysko 2007 for a German news magazine; SagmeisterBrandner 2008 for Austrian TV news broadcasts; Schaefer 2019 for German radio morning shows). Additionally, attention has been drawn to a similar increase in the prominence of English lexis in the field of other-language advertising, print and online (see, e.g. Martin 2007; 2014 on the presence of 'English' in francophone advertisements). With regard to digital interpersonal media, there has been much commentary on how 'English' has substantially increased its presence and influence in other-language social communication, such as especially that via chat and Facebook (for further discussion, see below).

The intended meanings signalled by the selective use of English lexical substance in both oral and visual media have been often interpreted as predominantly affective-indexical in essence. For example, for other-language print advertising Kelly-Holmes (2005) concludes that "English seems fetishized with a number of associations such as modernity, internationalism or cosmopolitanism, trendiness and success" $(2005,104)$. Specifically, for German 'bilingual narratees' of advertisements for goods and services the effect of English lexical substance in print advertisements is a signalling of 'international orientation, 'future orientation', 'success orientation', 'sophistication' and 'fun orientation' 
(Piller 2001, 163). With regard to the web advertising of internationally oriented French corporations (in the oil, banking, electricity, retail, luxury goods and food sectors), Martin (2014) concludes that " $\mathrm{i}] \mathrm{n}$ this environment, English is functioning as both a global access symbolizing modernity, global interconnectivity and professional mobility and a pair language for locally meaningful code-mixing, satisfying the creative and innovative needs of advertising" (2014, 149).

However, in radio and television broadcasting, especially where journalists have partial freedom of expression, it has been shown that while the use of anglicisms may be partly motivated by associations with modernity, more often than not are they employed in the absence of equivalent vocabulary in the other-language or for stylistic reasons such as pure variation in vocabulary use, or intensification of meaning (of the other-language item), or often because the anglophone items are simply shorter than their other-language synonyms (see Schaefer $(2019,78-84)$ for German radio language). Such differences in the anglophone practices of other-language advertising and broadcasting may be put down to the predominant semantic nature of language being communicated, i.e. 'appellative' in the case of advertising, 'informative' in the case of broadcasting. In other words, by and large it is 'English' for its connotative force that is selected in advertising and English for its denotative force that is employed in broadcasting.

\section{The Visualisation of Language and Multilingualism}

The previously referred-to 'social turn' in linguistics of the late $20^{\text {th }} /$ early $21^{\text {st }}$ century has been directly accompanied by a marked 'visual turn' in sociocultural studies of the same period addressing the optical nature and impact of the increasing visualisation of cultural artefacts and practices. Indeed, a reflected visualisation of language can be noted in the cases of advertising as discussed, where in the other-language texts " $[t]$ he authority of the English is usually reinforced by paralinguistic devices such as large print, colour, uncommon fonts and forms in print media" (Piller 2001, 163); in the same vein, Martin (2007) highlights the 'visual glossing' of English by manipulation of the typography to visually enhance the semiotics of the anglophone message (2007, 183-185). That is, the multilinguality of the texts is not only verbally expressed, but, significantly, visually intensified and as such must be seen as constituting part of the total impact of the advertisement, together with the other graphic images present. In this sense, the 'English' in such advertisements not only carries semiotic significance via the connotations of its verbal essence but additionally via its very visual appearance (cf. James 2014, 22). As such, the 'English' then becomes part of a bi-modal display of the verbal and the visual, the linguistic and the graphic, as both 'verbal image' and 'visual text' (James 2014, 19). Another sphere of 
public communication where an increased visualisation of multilingualism may be noted is in the so-called 'linguistic landscapes' of public signage. Such signage may be primarily institutionally or commercially created, i.e. with primarily either an 'informative' or 'appellative' semantic force, respectively. Research on this area has the aim of revealing the relative socio-political and sociocultural status of the languages present in a multilingual polity, such as by an analysis of the frequency of multilingual signs, the positioning, size and even font type of the languages used on the signs relative to each other (cf. e.g. Coupland 2012 for the bilingual linguistic landscape of Wales).

Of particular interest is the research of Rasinger (2014), who presents a detailed empirical analysis of the linguistic landscapes of Southern Carinthia (Austria), specifically of the Rosental/Rož, in which civic, commercial and church "frames" of the signages are compared for the occurrence of German and Slovene. He comes to the conclusion that while the officially regulated topographic signs of the civic "frame" are bilingual and the church signs predominantly so, the much more frequent commercial signage is predominantly monolingual German. This, he claims might indicate that "Slovene seems to be assigned a low sociosymbolic value" $(2014,598)$, which, however, he contrasts with recent "trends that point towards an increase in Slovene use and more positive perception" $(2014,598)$, i.e. ultimately questioning any simplistic link between the public presence of multilingualism and practised sociolinguistic realities. The visualisation of multilingualism is addressed by Kelly-Holmes (2014) in terms of linguistic 'fetishisation', i.e. "the phenomenon of using languages for symbolic (fetishised) rather than utility (instrumental-communicative) purposes in commercial texts (2014, 135 and 139-140). As prime examples of this visual multilingualism, she adduces 'foreign languages as visual', with the analysis of the use of French in a cider advertisement for an anglophone audience (2014, 141-143), 'minority languages as visual' with an analysis of the intended 'authenticity' effects in the marketing of pottery in the Irish language (2014, 147-148), and, of particular relevance for the present discussion, 'visual English' with an analysis of its global appeal as used in a Japanese-addressed advertisement for (Japanese) cars. Here she concludes, significantly for the present discussion, that "English has come to be ideologised as separate to multilingualism and not indexical of any particular country or "otherness"” (2014, 143).

Further, on 'visual English', Schlick (2002; 2003) presents an empirical study of English in shop signs in other-language(s) countries, comparing its presence in main city centre shopping locations in Klagenfurt (Austria), Ljubljana (Slovenia) and Udine (Italy), concluding inter alia that for the period 2000-2001, the proportion of 'English' in the three cities decreased in the same order as listed (from presence in 36\% of shop signs in Klagenfurt to $34 \%$ in Ljubljana to $25 \%$ in Udine). 
Following on from this research, but within a larger scale 'linguistic landscape' framework extended to include ethnographic perspectives on multilingual signage, Wehr (2020) investigates public commercial advertising in Klagenfurt displaying English and analyses its presence and form with relation to the German present in the texts. In addition, a questionnaire survey reveals the attitudes of readers of the advertisements to the English deployed in them. In general, it is shown that the English provides additional rather than equivalent information to the German and is significantly more present in texts signalling (cultural) events than those signalling consumer products. With regard to readers' attitudes, there is overall a general acceptance of the presence of English in the advertisements, making the product presented in English 'more attractive and fashionable' (2020, 180), also, in the respondents' words e,g., "appealing", "modern", "colourful" (sample female responses) or e.g." "international", "concise", "informative" (sample male responses), indicating in the author' words, generally a more 'emotional' set of responses from females and 'intelligibility' responses from males $(2020,184)$. Clearly, these descriptions tie in well with the (affective-indexical) associations of the 'English' in the print and web advertising studies of Piller (2001), Kelly-Holmes (2005) and Martin (2014) discussed above.

Finally, James (2016) analyses the semiotics of both the verbal and visual impact of 'English' as incorporated in the graphic touristic logos of Slovenia, Croatia and FriuliVenezia-Giulia (Italy), where 'code-mixing' mutates to 'mode-mixing' (2016, 267-270), i.e. where 'English' displays again a bi-modal identity.

\section{The Digitalisation of Social Communication and Multilingualism}

The mediatisation and visualisation of multilingualism combine to characterise multilingualism practices online, in particular interpersonal communication via the social media, which in turn typically manifests the linguistic hybridisation of code-mixing/'translanguaging' as previously discussed above. In addition, the expressive constraints imposed by the medium itself, i.e. those of characters available on an electronic keyboard (for instance, the availability of different scripts and non-verbal signs) equally shape the form of messages sent. Favoured channels/genres of social communication via the internet such as Facebook, Instagram and Snapchat furthermore promote a presentational style of discourse on the part of the users, geared to the culling of approval (LIKES!) of addressees, i.e. it involves the exercise of Goffman's (1959) 'impression management' for image optimisation in everyday communication. In the most general sense, "[d]igital writing is about writing oneself into being" (Boyd 2008, 14), and in the social media the creation 
of this identity/these identities occurs online via a reflected dramaturgical 'presentation of self' (Goffman 1959), where code-mixing/translanguaging is a "resource for identity marking and self-positioning for multilingual participants" (Lee 2017, 45). With the social media genres generally promoting a humorous and ludic style of language communication, the situation is often such that "[f] or multilingual web users, resources to play with or remix include languages, orthographies, and typographies. In multilingual digital writing, playing with words and combining scripted and typographical symbols from different languages allow users to perform and represent aspects of identities" (Lee 2017, 64). Indeed, empirical studies have confirmed this: cf., e.g. for Facebook postings of younger generation users switching between Thai in original alphabetic script, in Romanised script and English (Seargeant, Tagg and Ngampramuan 2012); for users switching between original Greek, "Engreek" (Greek alphabet English) and English (Spilioti 2014); for users switching between Mongolian in original Cyrillic script, in Romanised script and English (Dovchin 2015); and for users switching between Nepali in Romanised script (instead of customary Devanagari) and English (Sharma 2012) - all for the purpose of creating and expressing particular personal identities/images in contexts of the ongoing communication.

\section{Data Analysis 1}

For a first illustration, an excerpt from the last-named study (Sharma 2012) is reproduced here, in which the Facebook postings are of college students in Kathmandu, Nepal, all of whom have attended an English-medium secondary school. Pratik is male, Deepika and Uma female and all have Nepali as their primary offline language. The topic of the exchange is earning money. English translations of the Nepali are represented in italics. 


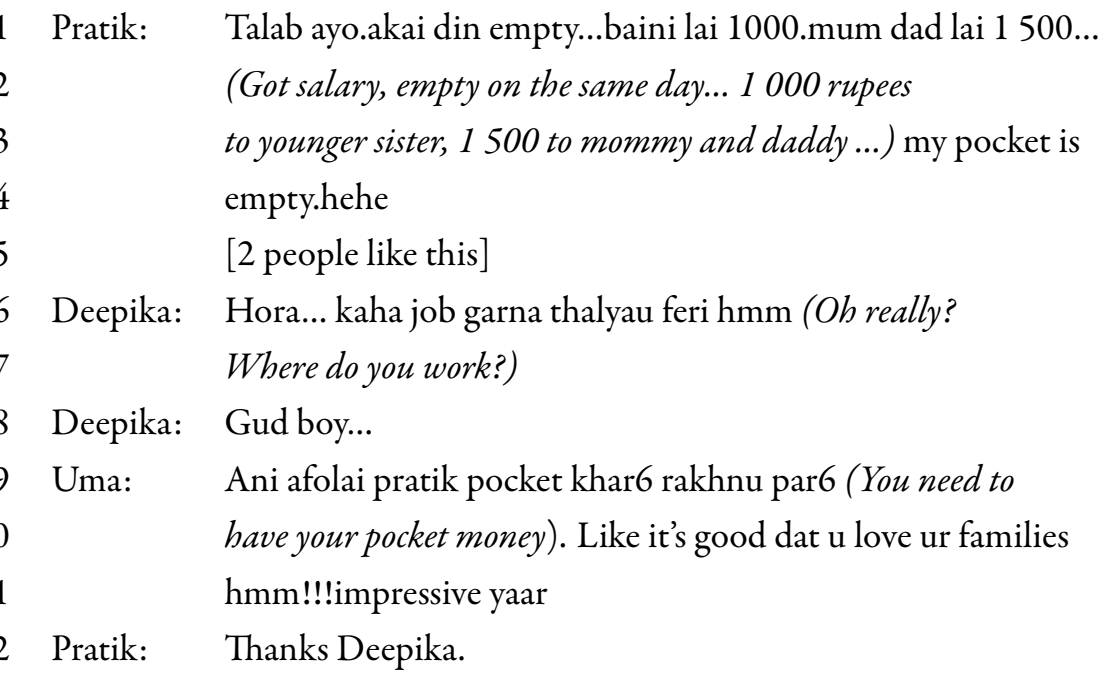

Figure 1: Excerpt 6 - Salary and empty pocket, lines 1-12 (Sharma 2012, 497).

The main framing forms are in Nepali syntax with English lexical insertions (empty, mum dad in line 1; job in line 6; pocket in line 9). Additionally, there are quasi-formulaic utterances in English (my pocket is empty, lines 3-4; Gud boy, line 8; Like it's good dat u love ur families, line 10; impressive, line 11; and Thanks Deepika, line 12). In general, it would seem that the informational content of the messages is expressed in Nepali, with English expressing meanings of a more affective nature but nonetheless salient to the developing exchange (empty, mum dad, my pocket is empty, Gud boy, pocket, Like it's good dat u love ur families, impressive, Thanks). The word job might be considered to be an internationalism. The filler $\mathrm{hmm}$ (twice) and the discourse particle Like are anglophone and the dat, $u$ and ur typically abbreviated forms for "that", "you" and "your" employed in social media 'English'. In line 11, yaar is the Hindi term for "buddy" or "friend". The filler hehe (line 4) would appear to be nepalophone.

English, which in Nepal is publicly present in the media and various internationally oriented domains of activity (Sharma 2012, 485), here adds a confirmatory affective dimension to the main topic of the exchange and serves to couch the message in an empathetic mode of discourse. All three participants employ anglophone individual words, phrases and sentences. Linguistically, Sharma concludes that the participants are employing a 'mixed code' (following Auer 1999), who "draw on multiple communicative resources in order to socially position themselves within the specific context of Nepalese society" (2012, 500), enacting their bilingual identities via code-mixing $(2012,496)$. 'English' as such then expresses both indexical and affective dimensions of personal meaning, and both a context-free and context-dependent semiotics (see also previous discussion 
above under From code-mixing to translanguaging). Both English and Nepali are 'partlanguages' discoursally but 'whole languages' by external reference, the participants being 'bilingual' in the conventional sense, while in Nepali society most likely being selectively 'domain-monolingual' at the same time.

With regard to the identities and subjectivities being manifested by the language users, one may concur with Harissi, Otsuji and Pennycook's analysis (2012) of multilingual social communication that "identity [...] is a question of group identification, subjectivity has to do with the discursive formation of the subject" $(2012,530)$. In the present example participant identities are established as belonging to the locally oriented Nepali-using and globally oriented English-using sociocultural communities, and participant subjectivities, i.e. "our conscious or unconscious sense of self as mediated through symbolic forms" (Kramsch 2009, 17), are here constructed via anglophone and nepalophone communication. In summary, one may again conclude with Harissi, Otsuji and Pennycook (2012) that while "[s] ubjectivities are performatively realized using tools of apparent fixity", analysis must seek to "understand the relationship between the fluid acts participants engage in while at the same time also deploying fixed, stable and sometimes stereotypical images of languages, people and cultures" (2012, 539).

As a postscript to the present discussion, it must be remembered that the nepalophone communication is via Romanised (i.e. 'internationalised'?) script, which can be seen as equivalent to an accented Nepali in the oral domain. The anglophony deployed is actually anglography in its standard script and orthography, with the exception of the social media-favoured substitutions and perhaps mildly transgressive spellings of ' $d$ ' in dat and the rebus spellings of $u$ and $u r$, which thereby signal nonetheless that the 'English' employed is that of digital anglography, i.e. with both a verbal and visual identity. In this respect, the anglography may be compared to other sign systems with their visual identity in this medium such as emojis and emoticons (although not shown in this particular data) and perhaps, significantly, sharing an affective semiotics in the discourse with them (for further discussion, see James 2014).

\section{Data Analysis 2}

The second short excerpt is reproduced from a corpus of the Facebook postings of lateteenage secondary school students of Greek origin in Hamburg, Germany, who are bilingual in Greek and German, but have the latter as their primary offline language of communication. 'Zach' initiates the exchange to which 'F1', a 'friend', reacts. The topic of the exchange is the participants' free time activities. Translations into English are in italics. Zach posts a U.S. music videoclip with the rappers' names given (T-Pain featuring $\mathrm{Ne}$ $Y o u$ ) and the title, the last word of which, $O N$, is capitalised relative to the original and 
1 Video title T-.Pain feat. Ne-You - Turn All the Lights ON

Zach Gib ihm $\& \delta \dot{\omega} \sigma \varepsilon$. Turn all the lights on!!

[German] Give him \& [Greek] give it, Turn all the

Lights on!!

2

Hast du dich vom We noch nicht erholt mit

party machen : $:$

Haven't you yet recovered from partying over the

weekend?

3 Zach Du kennst mich, bei mir heißt es non-stop all night long (2)

You know me, with me it's like non-stop all night

long

Figure 2: Example (5) - Zach's wall, February 2010 (Androutsopoulos 2014, 68).

therefore highlighted by Zach, perhaps in contrast to "off". Also, a full stop is inserted between $T$ and Pain relative to the original. Androutsopoulos comments on "the revoicing of the videoclip title in the initiating post, but also the way responders recontextualize this input as a resource to negotiate local relationships" $(2014,68)$. This revoicing is preceded by the imperative forms German Gib ihm and Greek $\delta \dot{\omega} \sigma \varepsilon$ linked by ampersand $\&$ as Zach's exhortations to perhaps an imaginary DJ to play this music. The near repetition of the germanophone form in Greek could well be seen as serving the intensification of its semantic impact via an insider-shared 'other' language, underscored by the use of the original Greek alphabet. The exhortation mode is compounded by two exclamation marks following the repeat of the clip's title, which is thereby appropriated as contextual direct speech. F1's questioning comment links with the partying associations evoked by reference to the videoclip as practised by Zach - here one notes the abbreviated We form for "Wochenende" and the employment of a smiling emoticon following the comment, as an affective softener to the mildly confrontative formulation of the question itself. The word party can be taken as an internationalism. In his response Zach then acknowledges F1's familiarity with his partying predilections with Du kennst mich, completed with the anglophone non-stop all night long as a pseudo-quote introduced by bei mir heißt es. A smiley is added then to confirm the friendly intention of the message. In terms of punctuation use, it is notable for social media communication practices that all turns begin with a capital letter, that a full stop separates Zach's two utterance units, that a comma is used after Du kennst mich, and a hyphen is employed in non-stop. However, and in con- 
trast, no question mark is used at the end of Fl's comment and no full stop is used at the end of Zach's reply.

Regarding the form and function of the 'English' displayed, it indeed has a quotative character via the intertextuality/intermediality it employs, associating with the music and clubbing/partying practices of younger generations (the very title of the rap itself reflecting a move - 'turning the lights on' - that could signal the closing of such clubbing/partying/disco sessions). 'English' then is here a domain-specific formulaic linguistic resource, linking to the mediality of popular entertainment and personal enjoyment and where with rap music it expresses the lyrics of the present subcultural semiotics directly. In multimedial social postings of the kind analysed (i.e. videoclip plus verbal communication), it is both anglophony and anglography, partially in parallel, that signal the intended meanings.

The language users here are employing a 'mixed code' of locally oriented German plus Greek, with selective adduction of globally oriented 'English' as a translanguaging practice. Both German and Greek are 'part-languages' discoursally but 'whole languages' by external reference to the offline practices of the participants, the users being 'bilingual' in the conventional sense. 'English' is here purely discoursal in function, signalling a context-dependent semiotics, where any indexicality is 'filtered' via the affective dimension it accrues in the ongoing exchange. With reference to the discussion of the previous data above, it may be concluded that the present users' sociocultural and sociolinguistic identities are here firmly German and Greek as these provide a context-free semiotics, whereas their subjectivities are formed via German, Greek and English.

\section{Multilingual Practices and English anno 2020}

Reference has been made above to the 'social turn' in linguistics and the 'visual turn' in sociocultural studies of the late $20^{\text {th }} /$ early $21^{\text {st }}$ centuries and to these may be added a general 'multilingual turn' in applied linguistics of the same period, in which both competences in, and combined practices of, Various Tongues have been revalued and subsequently celebrated as tokens of a rich heterogeneity of sociocultural communication (cf. May 2014). The individualisation of societal practices, including the lingual, with their prominent cultivation of self-image and self-presentation, together with the marked visualisation and mediatisation of language as discussed, has led to new modes of heteroglossic/polyphonic exchange, in which the linguistic can combine with other semiotic resources such as the graphic, the verbal modality with the visual, and where language as 'medium' can link in with other media in the total communicative event. 
Multilingualism is no longer only mediated via sociocultural practices, but is itself mediatised, and it has been shown above how this has led to multilingual communication becoming an increasingly reflected activity in which attention is paid not only to the expression of linguocultural identities as such but equally to the expression of the discoursally shaped subjectivities of language users. It has been noted that in scenarios of verbal exchange, while certain languages can take on both the role of identity- and subjectivitymarker, others are restricted to the role of subjectivity signalling, such as English in the second data analysis above. It has been further suggested in the data analysis that 'English' can be employed primarily for the expression of affective meaning locally in an exchange, to which one may add that any indexical meaning accruing to it would be with reference to a - largely virtual - supralocal/global community of 'cool', etc. And while such observations have been confirmed in other research referred to above, it must be remembered that this primarily 'modal' rather than 'codal' role of anglophony/anglography in multilingual communication is the case where English is not a socio-politically integrated language in the sociocultural reference world of the participants of an exchange (such as its status as a 'foreign language' in Germany, with reference to Data Analysis 2). In contexts where English is recognised as an integral means of communication in the societies in which the participants of the exchanges are primarily socialised (such as its status as a 'second language' in Nepal, with reference to Data Analysis 1), it then fulfils a 'codal' (as well as 'modal') role as a 'whole language' and as such constitutes a resource for the linguistic expression of a full range of sociocultural semiotics.

\section{Conclusion}

Returning once more to Vielerlei Zungen (2003), it may be noted that a number of conclusions drawn on the cases of mediated multilingualism examined in the contributions do clearly adumbrate the main conclusions drawn in the present analysis. Practised multilingualism seen as 'subversive', 'relations-changing' between component languages, and perhaps, in particular, as constituting itself an aterritorial space and couched as (masked) performance, all ring true in the light of the findings of 2020. Furthermore, code-switching and code-mixing viewed as normal multilingual practice, pluralistic and shifting language identities as well as the tentative suggestions expressed on discursively created subjectivities and the role of English therein are here confirmed. In final conclusion one may note positively that in the time between, practices of socially sanctioned simultaneous multilingualism have intensified, diversified and demoticised, where the agency of 'English' has been facilitative. 


\section{References}

Androutsopoulos, Jannis. 2014. "Languaging when contexts collapse: Audience design in social networking." Discourse, Media and Context (4-5): 62-73.

Androutsopoulos, Jannis. 2016. "Mediatization and sociolinguistic change. Key concepts, research traditions, open issues." In Mediatization and Sociolinguistic Change, edited by Jannis Androutsopoulos, 3-48. Berlin: De Gruyter.

Appadurai, Arjun. 1996. Modernity at Large: Cultural Dimensions of Globalization. Minneapolis: University of Minnesota Press.

Auer, Peter. 1999. "From codeswitching via language-mixing to fused lects: Towards a dynamic typology of bilingual speech." International Journal of Bilingualism 3 (4): 309-332.

Blommaert, Jan. 2010. The Sociolinguistics of Globalization. Cambridge: Cambridge University Press.

Boyd, Dana. 2008. "Facebook's privacy trainwreck." Convergence: The International Journal of Research into New Media Technologies 14 (1): 13-20.

Coupland, Nikolas. 2012. "Bilingualism as display: The framing of Welsh and English in Welsh public spaces." Language in Society 41 (1): 1-27.

Dovchin, Sender. 2015. "Language, multiple authenticities and social media: The online language practices of university students in Mongolia." Journal of Sociolinguistics 19 (4): 437459.

Goffman, Ervin. 1959. The Presentation of Self in Everyday Life. New York: Doubleday.

Grosjean, François. 1989. "Neurolinguists beware! The bilingual is not two monolinguals in one person." Brain and Language 36 (1): 3-15.

Halliday, Michael. 2007. "Applied linguistics as an evolving theme." In Language and Education: Collected Works of M. A.K. Halliday, edited by Jonathan Webster, 1-19. London: Continuum.

Harissi, Maria, Emi Otsuji and Alastair Pennycook. 2012. "The performative fixing and unfixing of subjectivities." Applied Linguistics 33(5): 524-543.

James, Allan, ed. 2003. Vielerlei Zungen. Mehrsprachigkeit + Spracherwerb + Pädagogik + Psychologie + Literatur + Medien. Klagenfurt/Celovec: Drava.

James, Allan. 2009. "Theorising English and globalisation: Semiodiversity and linguistic structure in Global English, World Englishes and Lingua Franca English.” Apples - Journal of Applied Language Studies 3 (1): 79-92.

James, Allan. 2014. "English as a visual language: Theorising the social semiotics of anglography in polylingual texts." English Text Construction 7 (1): 18-52.

James, Allan. 2016. "From code-mixing to mode-mixing in the European context." World Englishes 35 (2): 259-275.

Jörgensen, Normann. 2008. "Polylingual languaging around and among children and adults." International Journal of Multilingualism 5 (3): 161-176.

Kelly-Holmes, Helen. 2005. Advertising as Multilingual Communication. Basingstoke: Palgrave Macmillan.

Kelly-Holmes, Helen. 2014. "Linguistic fetish: The sociolinguistics of visual multilingualism." In Visual Communication, edited by David Machin, 135-151. Berlin: De Gruyter Mouton. 
Kramsch, Claire. 2009. The Multilingual Subject. Oxford: Oxford University Press.

Lee, Carmen. 2017. Multilingualism Online. London: Routledge.

Li, Wei. 2017. "Translanguaging as a practical theory of language." Applied Linguistics 39 (1): 1-22.

Martin, Elizabeth. 2007. “'Frenglish' for sale: Multilingual discourses for addressing today's global consumer." World Englishes 28 (2): 170-190.

Martin, Elizabeth. 2014. "Linguistic and cultural hybridity in French web advertising." In The Global-Local Interface and Hybridity. Exploring Language and Identity, edited by Rani Rubdy and Lubna Alsagoff, 133-152. Bristol: Multilingual Matters.

May, Stephen, ed. 2014. The Multilingual Turn. Implications for SLA, TESOL and Bilingual Education. London: Routledge.

Onysko, Alexander. 2007. Anglicisms in German: Borrowing, Lexical Productivity and Written Codeswitching. Berlin: de Gruyter.

Pennycook, Alistair. 2007. Global Englishes and Transcultural Flows. London: Routledge.

Piller, Ingrid. 2001. "Identity constructions in multilingual advertising." Language in Society 30(2): 153-186.

Rampton, Ben. 1995. Crossing: Language and Ethnicity among Adolescents. London: Longman.

Rasinger, Sebastian. 2014. "Linguistic landscapes in Southern Carinthia (Austria)." Journal of Multilingual and Multicultural Development 35 (6): 580-602.

Sagmeister-Brandner, Sonja. 2008. Breaking News: So kommen englische Wörter ins Radio und Fernsehen. Bern: Peter Lang.

Schaefer, Sarah. 2019. "Anglicisms in German media: Exploring catachrestic and non-catachrestic innovations in radio station imaging." Lingua 221: 72-88.

Schlick, Maria. 2002. “The English of shop signs in Europe.” English Today 18 (1): 3-7.

Schlick, Maria. 2003. “The English of shop signs in Europe.” English Today 19 (2): 3-17.

Seargeant, Philip, Caroline Tagg and Wipapan Ngampramuan. 2012 "Language choice and addressivity strategies in Thai-English social network interactions.” Journal of Sociolinguistics 16 (4): 510-531.

Sharma, Bal Krishna. 2012. "Beyond social networking: Performing global Englishes in Facebook by college youth in Nepal." Journal of Sociolinguistics 16 (4): 483-509.

Spilioti, Tereza. 2014. "Greek-Alphabet English: Vernacular transliterations of English in social media." In Opening New Lines in Applied Linguistics. Proceedings of the 46th Annual Meeting of the British Association for Applied Linguistics, edited by Bernadette O'Rourke, Nicola Bermingham and Sara Brennan, 435-446. London: Scitsiugnil Press.

Wehr, Iryna. 2020. "English as a written representation of the visual mode. A study of public advertising in Klagenfurt, Austria." In Place-Making in the Declarative City, edited by Beatrix Busse, Ingo H. Warnke and Jennifer Smith, 171-188. Berlin: de Gruyter. 